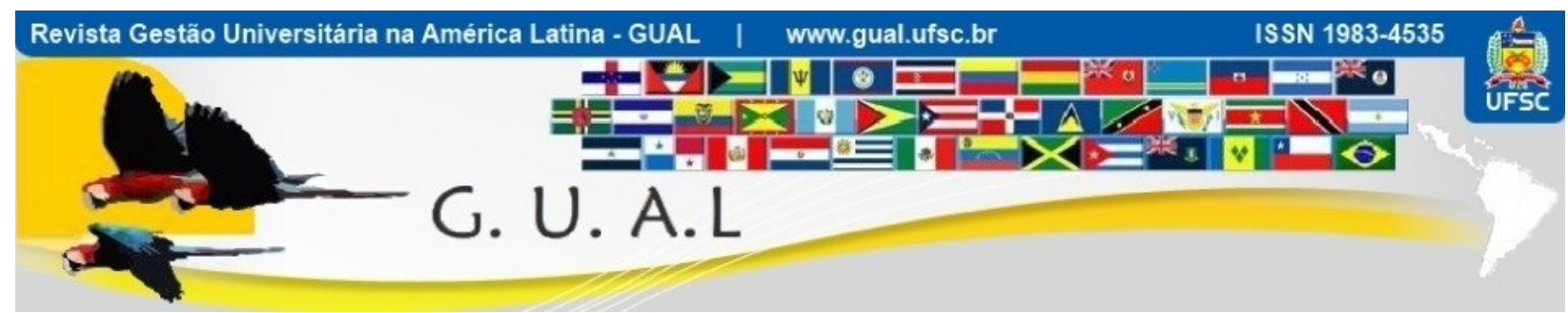

DOI: http://dx.doi.org/10.5007/1983-4535.2014v7n1p234

\title{
CARACTERÍSTICAS BIBLIOMÉTRICAS E SOCIOMÉTRICAS DE PUBLICAÇÕES DA ÁREA AMBIENTAL EM CONGRESSOS E PERIIODICOS NACIONAIS
}

BIBLIOMETRIC AND SOCIOMETRIC CHARACTERISTICS IN PUBLICATIONS OF
THE ENVIRONMENTAL AREA IN CONFERENCES AND NATIONAL JOURNALS

Ilse Maria Beuren, Doutora

Universidade Federal do Paraná - UFPR

ilse.beuren@gmail.com

Márcia Zanievicz Silva, Doutora Universidade Regional de Blumenau - FURB marciaza@gmail.com

Andréia Carpes Dani, Mestra Universidade Regional de Blumenau - FURB andreiacarpesd@yahoo.com

Nilton Roberto Kloeppel, Mestre Universidade Regional de Blumenau - FURB niltonkloe@uol.com.br

Recebido em 01/agosto/2013

Aprovado em 14/novembro/2013

Sistema de Avaliação: Double Blind Review

Esta obra está sob uma Licença Creative Commons Atribuição-Uso. 


\title{
RESUMO
}

O estudo objetiva examinar características bibliométricas e sociométricas de publicações da área ambiental no Congresso USP de Controladoria e Contabilidade, EnANPAD e em periódicos de Administração e Contabilidade no período de 2000 a 2010. Pesquisa descritiva com abordagem quantitativa foi realizada por meio de pesquisa documental. Os resultados da pesquisa bibliométrica destacam que: i) o volume de publicações sobre o tema no EnANPAD aumentou significativamente no decorrer do período analisado; ii) os periódicos O\&S, RAE, RAUSP e REAd apresentam tendência ascendente no volume de publicações sobre o tema; iii) quanto aos procedimentos metodológicos, o Congresso USP e o EnANPAD priorizaram estudos de caso e survey e os periódicos estudos teóricos, mas em todos prevaleceu a abordagem qualitativa; iv) dentre as categorias da temática ambiental prevaleceu a Gestão Ambiental e evolução nas publicações sobre Evidenciação Ambiental. Os resultados da pesquisa sociométrica revelam que a configuração estrutural dos relacionamentos dos autores prepondera nos congressos e há alguns autores que possuem laços de publicações com autores de outros periódicos. Conclui-se que as características bibliométricas e sociométricas das publicações da área ambiental sinalizam que o tema continua em evidência e que a configuração estrutural dos relacionamentos dos autores apresenta lacunas principalmente nos periódicos pesquisados.

Palavras-chave: Características. Publicações. Área ambiental. Bibliometria. Sociometria.

\begin{abstract}
The goal of this study is to examine sociometric and bibliometric characteristics in publications of the environmental area in the USP Congress of Controlling and Accounting, EnANPAD and in journals of Administration and Accounting in the period from 2000 to 2010. A descriptive research with quantitative approach was carried out through desk research. The results of the bibliometric survey highlighted that: i) the volume of publications on the topic in the EnANPAD increased significantly during the analyzed period; ii) the journals $\mathrm{O} \& \mathrm{~S}$, RAE, RAUSP and REAd present upward trend in the amount of publications on the subject; iii ) regarding the methodological procedures, the USP Congress and the EnANPAD prioritized case studies and survey and the journals the theoretical studies, but the qualitative approach prevailed in all of them; iv) among the categories of the environmental issues, the Environmental Management and the development in the publications on Environmental Disclosure prevailed. The results of the sociometric research show that the structural configuration of relationships of the authors prevails in the congresses and there are some authors who have ties of publications with authors from other journals. It is concluded that the bibliometric and sociometric characteristics of the publications of the environmental area signal that the subject remains in evidence and that the structural configuration of the relationships of the authors has gaps mainly in the journals studied.
\end{abstract}

Keywords: Features. Publications. Environmental area. Bibliometrics. Sociometry. 


\section{CARACTERÍSTICAS BIBLIOMÉTRICAS E SOCIOMÉTRICAS DE PUBLICAÇÕES DA ÁREA \\ AMBIENTAL EM CONGRESSOS E PERÍODICOS NACIONAIS \\ DOI: http://dx.doi.org/10.5007/1983-4535.2014v7n1p234}

\section{INTRODUÇÃO}

A sociedade convive com o fato de que os recursos naturais são escassos e que a ação do homem interfere significativamente no equilíbrio natural e impacta na qualidade de vida. Em relação a esse aspecto, Bebbington e Gray (2001) afirmam que a atual organização social, econômica e política mundial não é sustentável, em qualquer sentido, mesmo que alguns países sejam sustentáveis, o mundo como um todo não o é.

A sociedade, ao longo das últimas décadas, tem desenvolvido ações com o objetivo de minimizar ou reduzir a interferência danosa do homem no meio ambiente. Tal processo gera impacto nas empresas, sobretudo naquelas que exercem atividades poluidoras. $O$ que a sociedade almeja é encontrar uma forma de satisfazer as necessidades do presente sem comprometer a capacidade das futuras gerações de satisfazer suas próprias necessidades (COMISSÃO MUNDIAL SOBRE MEIO AMBIENTE, 1987).

Em razão do exposto, diversas áreas do conhecimento têm se mobilizado em prol desta causa, com a finalidade de contribuir com esse processo. Assim, a gestão ambiental e a busca pela sustentabilidade tornaram-se elementos de atenção por parte dos gestores, mesmo que muitas vezes motivados por interesses diversos ou obrigados por força legal ou social.

A contabilidade se insere no debate em curso ao priorizar sua atenção no que foi denominado de Contabilidade Ambiental, cujo destaque, segundo Gray, Bebbingtone Walters (1993) e Mathews (1997) tornou-se relevante já no final da década de 1980 e seu tema passou a ter um importante papel nas deliberações dos profissionais da área. Por conseguinte, as pesquisas em contabilidade ambiental e sustentabilidade se inserem nesse debate, dentre outros aspectos, por discutir qual o papel da contabilidade nas mudanças organizacionais necessárias ao desenvolvimento de uma sociedade com foco na sustentabilidade (GONZALEZ; BEBBINGTON, 2001).

Em âmbito internacional, no que concerne ao desenvolvimento de pesquisas sobre contabilidade ambiental, identificaram-se estudos que realizaram pesquisas bibliométricas e sociométricas nesta área. Mathews (1997) analisou a literatura internacional sobre contabilidade social e ambiental. Seu estudo apresenta a evolução do tema na área contábil, comenta tendências observadas a partir da sua pesquisa, bem como, fornece uma ampla e detalhada literatura sobre o tema. Tal estudo foi realizado em um recorte longitudinal de 25 anos (1971 até 1996). Os estudos Gray, Kouhy e Lavers, (1995) e Parker (2005 e 2011) igualmente objetivaram investigar a evolução das pesquisas relacionadas ao tema. 


\section{CARACTERÍSTICAS BIBLIOMÉTRICAS E SOCIOMÉTRICAS DE PUBLICAÇÕES DA ÁREA \\ AMBIENTAL EM CONGRESSOS E PERÍODICOS NACIONAIS \\ DOI: http://dx.doi.org/10.5007/1983-4535.2014v7n1p234}

No Brasil, os estudos bibliométricos e sociométricos sobre contabilidade ambiental se encontram em processo de desenvolvimento e crescimento. Tal fato é evidenciado por pesquisas como as de Gallon et al. (2007), que objetivou examinar as características metodológicas de artigos científicos da área ambiental no período de 2000 até 2006. Há também o estudo de Sgarbi et al. (2008), que investigou os jargões da sustentabilidade presente nas pesquisas publicadas entre os anos de 2003 e 2007. Gallon et al. (2008) objetivaram investigar a produção científica em administração sobre a temática ambiental nos periódicos nacionais e no EnANPAD, no período de 2000 até 2006.

Ainda no Brasil, mas tendo como campo de pesquisa publicações internacionais, Murcia (2010) apresentou uma revisão da literatura internacional acerca do tema disclosure ambiental, no período de 1997 a 2007. Em razão do crescente processo de inserção da contabilidade nas questões ambientais, acredita-se que nos últimos anos a pesquisa e as redes de pesquisadores sobre o tema de contabilidade ambiental tenham se ampliado e se modificado, comparativamente ao que foi evidenciado nos estudos anteriores.

Com base no exposto elaborou-se a seguinte questão de pesquisa: Quais as características bibliométricas e sociométricas de publicações da área temática ambiental socializadas no Congresso USP de Controladoria e Contabilidade e no EnANPAD e publicadas em periódicos da área de Administração e Contabilidade, no período de 2000 a 2010? Assim, o estudo objetiva examinar características bibliométricas e sociométricas de publicações da área ambiental no Congresso USP de Controladoria e Contabilidade, EnANPAD e em periódicos de Administração e Contabilidade no período de 2000 a 2010.

A relevância da pesquisa está no exame das características bibliométricas e sociométricas de publicações sobre a área temática ambiental, com ênfase no atual estado da arte dos estudos relacionados ao tema, as características metodológicas adotadas por tais estudos, as relações estabelecidas entre os pesquisadores, os pesquisadores mais prolíficos na área. Pesquisar as características bibliométricas e sociométricas destes estudos permite identificar áreas do conhecimento já consolidadas e lacunas ainda pouco exploradas, o que pode ser útil para o delineamento de futuras pesquisas.

Nos procedimentos metodológicos desta pesquisa, o destaque é para a incorporação de dados socializados em um evento científico nacional. Isto implica adotar a mesma estratégia de pesquisa para que os dados anteriores possam ser consolidados. Neste sentido, compilamse e complementam-se os dados relativos ao período de 2000 até 2006 da pesquisa de Gallon 


\section{CARACTERÍSTICAS BIBLIOMÉTRICAS E SOCIOMÉTRICAS DE PUBLICAÇÕES DA ÁREA \\ AMBIENTAL EM CONGRESSOS E PERÍODICOS NACIONAIS \\ DOI: http://dx.doi.org/10.5007/1983-4535.2014v7n1p234}

et al. (2007), ao invés de serem coletados novamente nas bases de dados. Esse fator, além de otimizar a fase de coleta dos dados, contribui para dar continuidade e aprimorar estudos já socializados, possibilitando, dentre outros aspectos, a operacionalização de pesquisas com recortes temporais maiores.

\section{CONTABILIDADE AMBIENTAL}

Segundo Mathews (1997), a contabilidade passou a dar atenção às questões ambientais, efetivamente, a partir do início da década de 70, evoluindo gradativamente em alguns temas e mantendo-se incipiente em outros. Em meados de 1990, segundo Mathews (1997), o tema constituiu-se como uma das áreas com maior crescimento de estudos e passou a despertar interesse muito além dos limites de acadêmicos e profissionais da contabilidade.

Em relação à evolução do tema, no âmbito internacional, o estudo de Mathews (1997) contribui ao apresentar uma ampla base de dados, contendo em torno de 300 referências bibliográficas relacionadas à contabilidade ambiental, tendo como marco inicial o estudo de Bowen (1953). No artigo, o autor avalia as publicações de periódicos internacionais publicadas no período entre 1971 e 1995. O volume das referências citadas no estudo de Mathews (1997) é segregado por ano de publicação, em que evidencia a evolução das publicações, bem como, a linha de tendência crescente, revelando a evolução e consequente relevância do tema no âmbito das pesquisas em contabilidade.

Calixto (2007, p. 12) adverte que "o destaque dado ao meio ambiente tem se intensificado em razão de resultados alarmantes de problemas como a poluição, esgotamento de recursos naturais e efeitos negativos sobre o clima e temperatura do planeta". Como consequência, a sociedade organiza-se e pressiona as empresas a, pelo menos, minimizarem seus impactos negativos na natureza. Tal afirmação pode ser comprovada por meio das inúmeras iniciativas voluntárias adotadas pelas empresas, no sentido de divulgarem seus investimentos em meio ambiente, educação, treinamento, dentre outros.

No que se refere ao conceito de contabilidade ambiental Gray et al. (1987 apud BELAU, 2001) descrevem que é o processo de comunicação dos efeitos sociais e ambientais das ações das organizações econômicas, de grupos de interesses especiais, dentro da sociedade e para a sociedade em geral. Como tal, implica estender a responsabilidade das organizações (particularmente das empresas), além do papel tradicional de fornecer uma informação aos proprietários de capital, em particular, os acionistas. 


\section{CARACTERÍSTICAS BIBLIOMÉTRICAS E SOCIOMÉTRICAS DE PUBLICAÇÕES DA ÁREA \\ AMBIENTAL EM CONGRESSOS E PERÍODICOS NACIONAIS \\ DOI: http://dx.doi.org/10.5007/1983-4535.2014v7n1p234}

De acordo com Souza e Ribeiro (2004, p. 55), “a Contabilidade Ambiental surge como uma vertente da Contabilidade Social e tem como objetivo gerar informações que envolvam a interação da empresa com o meio ambiente, e que sejam úteis para a tomada de decisão dos usuários internos e externos". Os autores acrescentam que a Contabilidade Ambiental, “enquanto veículo de divulgação das informações ambientais, pode oferecer ferramentas necessárias ao controle e divulgação do processo de gestão ambiental implantado pelas empresas, de acordo com os objetivos fixados".

A Contabilidade constitui-se como um instrumento de gestão ambiental, o que favorece a integração entre os aspectos ambientais na estratégia da empresa e na cadeia de decisão operacional (GONÇALVES; HELIODORO, 2005). Ainda, segundo os referidos autores, ela contribui para a promoção da transparência e geração de informações para os investidores. Depreende-se que de forma ampla a Contabilidade Ambiental precisa contemplar todos os elementos da temática ambiental, como as consideradas por Gallon et al. (2007): contabilidade ambiental, evidenciação ambiental, gestão ambiental e sustentabilidade.

O processo de divulgação das informações geradas pela contabilidade, de acordo com Ponte et al. (2007, p. 51), tem suscitado preocupações no que tange à qualidade da informação divulgada, que envolve "aspectos econômicos, financeiros, sociais, ambientais, de produtividade e de gestão, entre outros". Os autores destacam ainda que, a "análise da evidenciação dessas informações e o acompanhamento de sua evolução estão cada vez mais presentes nas discussões tanto acadêmicas, quanto empresariais e de órgãos, sejam públicos ou privados". Esta postura requer cuidados especiais por parte dos gestores e contadores.

No que tange à gestão ambiental, no decorrer dos anos, ela passou a fazer parte do contexto organizacional das empresas. Santos, Rocha e Santos (2006, p. 3) concebem-a como "um conjunto de medidas e procedimentos aplicados adequadamente para reduzir e controlar os impactos ambientais. Requer conhecimentos específicos para entender e realizar esse processo, criando um sistema de informação para registrar, medir e relatar suas ações".

Ao promover-se uma adequada gestão ambiental, as empresas se inserem na nova ordem social, que busca atingir a sustentabilidade social, econômica e ecológica. O que se almeja com os movimentos prol sustentabilidade é, segundo Jacobi (2003), encontrar uma forma de harmonizar os processos ambientais com os socioeconômicos.

Infere-se que, estando à temática ambiental inserida no contexto gerencial das organizações, ela deve ser contemplada por diversos enfoques e, consequentemente, ser 


\section{CARACTERÍSTICAS BIBLIOMÉTRICAS E SOCIOMÉTRICAS DE PUBLICAÇÕES DA ÁREA \\ AMBIENTAL EM CONGRESSOS E PERÍODICOS NACIONAIS \\ DOI: http://dx.doi.org/10.5007/1983-4535.2014v7n1p234}

observada pelos pesquisadores a partir dessas perspectivas. Neste estudo, fundamentado em estudos dedicados a abordar aspectos relacionados ao meio ambiente, consideraram-se as seguintes categorais de segregação dos enfoques da temática ambiental: contabilidade ambiental, evidenciação ambiental, gestão ambiental e sustentabilidade. Esta segregação é similar a adotada na pesquisa de Gallon et al. (2007).

\section{PROCEDIMENTOS METODOLÓGICOS}

O delineamento metodológico da pesquisa caracteriza-se como descritiva quanto aos objetivos, documental quanto aos meios e quantitativa quanto à abordagem do problema. Em relação à pesquisa descritiva, Vergara (1998, p. 45) comenta que nesse tipo de pesquisa expõem-se "características de determinada população ou de determinado fenômeno. Pode também estabelecer correlações entre variáveis e definir sua natureza. Não tem compromisso de explicar os fenômenos que descreve, embora sirva de base para tal explicação".

O universo da pesquisa compreendeu trabalhos socializados em congressos científicos brasileiros e artigos publicados em periódicos nacionais da área de Administração e Contabilidade, denominados de forma conjunta como publicações. A escolha dos eventos científicos e dos periódicos para fins de investigação é caracterizada como intencional e não probabilística e constituem-se nas mesmas obras investigadas na pesquisa de Gallon et al. (2007), que é o trabalho de referência adotado para o desenvolvimento do presente estudo.

Assim delimitou-se como amostra da pesquisa as publicações integrantes dos seguintes congressos: Congresso USP de Controladoria e Contabilidade e o Encontro da Associação Nacional de Pós-Graduação e Pesquisa em Administração (EnANPAD). E as publicações dos seguintes periódicos: Organizações \& Sociedade (O \& S), da UFBA; Revista de Administração Contemporânea (RAC), da ANPAD; Revista de Administração de Empresas (RAE), da FGV/SP; Revista de Administração de Empresas Eletrônica (RAE Elet.), da FGV/SP; Revista de Administração Pública (RAP), da FGV/RJ; Revista Brasileira de Administração (RAUSP), da USP; Revista Contabilidade \& Finanças (RC\&F), da USP; e, Revista Eletrônica de Administração (REAd), da UFRGS.

Na coleta dos dados, para o período de 2000 até 2006 este estudo utilizou-se dos dados coletados e socializados no artigo de Gallon et al. (2007). Tal procedimento foi possível em razão do referido artigo, que objetivava examinar as características metodológicas de artigos científicos da área ambiental, ter enfoque similar ao presente estudo. Procedendo-se então, a 


\section{CARACTERÍSTICAS BIBLIOMÉTRICAS E SOCIOMÉTRICAS DE PUBLICAÇÕES DA ÁREA \\ AMBIENTAL EM CONGRESSOS E PERÍODICOS NACIONAIS \\ DOI: http://dx.doi.org/10.5007/1983-4535.2014v7n1p234}

coleta dos dados relacionados aos períodos posteriores (2007 a 2010), por meio dos mesmos termos de busca do estudo de Gallon et al. (2007): meio ambiente, sustentabilidade, ecologia, bem como suas traduções e derivações.

$\mathrm{Na}$ sequência procedeu-se o enquadramento dos artigos em quatro temáticas ambientais, similarmente ao estudo realizado por Gallon et al. (2007), sendo: Contabilidade Ambiental, Evidenciação Ambiental, Gestão Ambiental e Sustentabilidade. Na análise dos dados coletados, também foi adotado procedimento similar para as caracterizações gerais e específicas das publicações analisadas, tais como: classificação de acordo com a fonte de coleta dos dados, abordagem metodológica adotada, autores mais prolíficos e obras mais referenciadas. No entanto, para a identificação dos sistemas relacionais utilizou-se a análise de redes por meio do software UCINET, técnica não utilizada no trabalho de referência.

\section{DESCRIÇÃO E ANÁLISE DOS RESULTADOS}

Nesta seção faz-se a descrição e análise dos resultados da pesquisa. Inicialmente, por meio da estatística descritiva, apresentam-se características gerais e específicas das publicações da área ambiental coletadas e analisadas, relativas ao período de 2000 a 2010 . Na seqüência, por meio da técnica de análise de redes, realizam-se análises da configuração estrutural dos relacionamentos dos autores nas categorias temáticas investigadas.

\subsection{CARACTERIZAÇÃO DAS PUBLICAÇÕES DA ÁREA TEMÁTICA AMBIENTAL COLETADAS E ANALISADAS}

Neste tópico apresenta-se a análise sobre: (i) publicações coletadas e analisadas do período de 2000 a 2010; (ii) número de artigos analisados conforme a base de coleta dos dados; (iii) classificação dos artigos em estudos teóricos e práticos; (iv) classificação dos artigos conforme fonte de coleta dos dados e setor de aplicação; (v) abordagem metodológica utilizada nos artigos; e (vi) número de artigos por categoria temática.

Primeiramente são expostas as características da produção científica da área ambiental divulgada por meio de trabalhos socializados em congressos e dos artigos publicados em periódicos no período de 2000 a 2010. Na Tabela 1 tem-se a descrição da amostra, com a relação de publicações selecionadas para verificação. 


\section{CARACTERÍSTICAS BIBLIOMÉTRICAS E SOCIOMÉTRICAS DE PUBLICAÇÕES DA ÁREA \\ AMBIENTAL EM CONGRESSOS E PERÍODICOS NACIONAIS \\ DOI: http://dx.doi.org/10.5007/1983-4535.2014v7n1p234}

Tabela 1 Publicações coletadas e analisadas relativas ao período de 2000 a 2010.

\begin{tabular}{|c|c|c|c|c|c|c|c|}
\hline \multirow[b]{3}{*}{ Base de coleta } & \multicolumn{6}{|c|}{ Número de artigos } & \multirow[b]{3}{*}{$\begin{array}{l}\text { Total } \\
(\%)\end{array}$} \\
\hline & \multicolumn{2}{|c|}{ Coletados } & \multicolumn{2}{|c|}{ Analisados } & \multicolumn{2}{|l|}{ Total } & \\
\hline & $\begin{array}{ll}2000 & a \\
2006 & \end{array}$ & $\begin{array}{ll}2007 & a \\
2010\end{array}$ & $\begin{array}{ll}2000 & a \\
2006 & \end{array}$ & \begin{tabular}{|ll}
2007 & a \\
2010 & \\
\end{tabular} & Coletados & Analisados & \\
\hline Congresso USP & 30 & 14 & 21 & 13 & 44 & 34 & \multirow{2}{*}{81,0} \\
\hline EnANPAD & 140 & 161 & 126 & 161 & 301 & 287 & \\
\hline $\mathrm{O} \& \mathrm{~S}$ & 2 & 6 & 2 & 6 & 08 & 08 & \multirow{9}{*}{19,0} \\
\hline RAC & 3 & 3 & 3 & 3 & 06 & 06 & \\
\hline RAE & 3 & 3 & 3 & 3 & 06 & 06 & \\
\hline RAE Elet. & 3 & 2 & 3 & 2 & 05 & 05 & \\
\hline RAP & 13 & 2 & 12 & 2 & 15 & 14 & \\
\hline RAUSP & 3 & 5 & 3 & 5 & 08 & 08 & \\
\hline $\mathrm{RC} \& \mathrm{~F}$ & 2 & 3 & 2 & 3 & 05 & 05 & \\
\hline REAd & 11 & 10 & 11 & 10 & 21 & 21 & \\
\hline Total Periódicos & 40 & 34 & 39 & 34 & 74 & 73 & \\
\hline Total Geral & 210 & 209 & 186 & 208 & 419 & 394 & 100,0 \\
\hline Média/ano & 30 & 52 & 26 & 52 & 38 & 36 & \\
\hline
\end{tabular}

Fonte: até o ano de 2006 adaptado de Gallon et al. (2007); de 2007 a 2010 dados da pesquisa.

Observa-se na Tabela 1 a quantidade de artigos coletados e utilizados para verificação nesta pesquisa. Para fins de analise foi utilizado um total de 394 artigos que continham pelo menos um dos termos pesquisados, sendo que destes $81 \%$ foram obtidos dos congressos (USP e EnANPAD) e o restante, $19 \%$ foram coletados nos oito periódicos listados. Ressalta-se ainda que, a diferença observada entre a quantidade de publicações coletadas e analisadas ocorre devido ao fato de que algumas das publicações encontradas com os termos pesquisados não tinham relação com o meio ambiente, e sim com outras áreas temáticas.

Comparativamente a coleta de dados realizada por Gallon et al. (2007), a exceção do Congresso USP, que manteve o mesmo volume médio de socializações, e do periódico RAP, que reduziu significativamente o volume de publicações sobre o tema, houve um acréscimo no número de artigos publicados. Fato esse que pode ser confirmado pelo número médio de publicações, que passou de 26 para 52, portanto, um crescimento de mais de $100 \%$. .

$\mathrm{Na}$ Tabela 2, demonstra-se o número de artigos analisados por ano e a respectiva base de coleta dos dados, considerado o período de 2000 a 2010. 


\section{CARACTERÍSTICAS BIBLIOMÉTRICAS E SOCIOMÉTRICAS DE PUBLICAÇÕES DA ÁREA \\ AMBIENTAL EM CONGRESSOS E PERÍODICOS NACIONAIS \\ DOI: http://dx.doi.org/10.5007/1983-4535.2014v7n1p234}

Tabela 2 Número de artigos analisados conforme a base de coleta dos dados do período de 2000 a 2010.

\begin{tabular}{|c|c|c|c|c|c|c|c|c|c|c|c|c|}
\hline \multirow{2}{*}{$\begin{array}{l}\text { Base de coleta } \\
\text { dos dados }\end{array}$} & \multicolumn{11}{|c|}{ Período } & \multirow{2}{*}{ Total } \\
\hline & 2000 & 2001 & 2002 & 2003 & 2004 & 2005 & 2006 & 2007 & 2008 & 2009 & 2010 & \\
\hline Congresso USP & - & 2 & 1 & 5 & 4 & 4 & 4 & 3 & 5 & 1 & 5 & 34 \\
\hline EnANPAD & 4 & 9 & 16 & 18 & 28 & 26 & 25 & 30 & 38 & 40 & 53 & 287 \\
\hline O\&S & 0 & 1 & 1 & 0 & 0 & 0 & 0 & 1 & 2 & 1 & 2 & 08 \\
\hline RAC & 0 & 0 & 0 & 0 & 1 & 1 & 1 & 0 & 2 & 1 & 0 & 06 \\
\hline RAE & 3 & 0 & 0 & 0 & 0 & 0 & 0 & 2 & 0 & 1 & 3 & 09 \\
\hline RAE Elet. & 0 & 0 & 0 & 1 & 1 & 1 & 0 & 0 & 1 & 1 & 0 & 05 \\
\hline RAP & 5 & 1 & 1 & 3 & 2 & 0 & 0 & 0 & 0 & 0 & 2 & 14 \\
\hline RAUSP & 0 & 0 & 0 & 1 & 1 & 1 & 0 & 2 & 1 & 1 & 1 & 08 \\
\hline $\mathrm{RC} \& \mathrm{~F}$ & 0 & 1 & 0 & 0 & 1 & 0 & 0 & 0 & 0 & 1 & 0 & 03 \\
\hline REAd & 1 & 0 & 5 & 0 & 2 & 2 & 1 & 4 & 2 & 4 & 0 & 21 \\
\hline Total Periódicos & 9 & 3 & 7 & 5 & 8 & 5 & 2 & 9 & 8 & 10 & 8 & 74 \\
\hline Total Geral & 13 & 14 & 24 & 28 & 40 & 35 & 31 & 42 & 51 & 51 & 66 & 395 \\
\hline
\end{tabular}

Fonte: até o ano de 2006 aAdaptado de Gallon et al. (2007) de 2007 a 2010 dados da pesquisa.

Verifica-se na Tabela 2 a distribuição das publicações relativas à área ambiental em congressos e periódicos no período dos onze anos analisados, de 2000 a 2010. Nota-se que os congressos possuem maior número de publicações sobre o tema, com 321 trabalhos socializados, em oposição aos periódicos, com 74 artigos publicados.

A quantidade de publicações sobre o tema ambiental no congresso USP manteve-se relativamente estável e no EnANPAD teve um aumento gradativo no número de publicações, principalmente a partir do ano de 2004. Um dos fatores que possivelmente contribuiu para esse aumento foi a criação da área temática de gestão social e ambiental, no ano de 2003.

Em relação aos periódicos, observa-se que a REAd foi a que apresentou maior número de publicações na área ambiental, com 21 artigos; seguida da RAP, com 14 artigos; e da RAE, com 9. Embora, por meio da análise de tendência, a RAP seja a única que apresentou tendência negativa em relação ao volume de publicação.

De modo geral, constatou-se nas bases analisadas uma evolução gradativa e contínua no número de publicações sobre a área ambiental. Na Tabela 3 apresenta-se a classificação das publicações de acordo com a respectiva base de coleta dos dados e se os estudos são teóricos ou práticos.

A distribuição dos artigos analisados conforme a classificação do tipo de estudo, se teórico ou empírico, está exposta na Tabela 3. O EnANPAD apresentou maior número de artigos com a classificação de estudos teóricos (69 conceitual, 28 ilustrativo e 25 conceitual aplicado), em comparação com o Congresso USP, que teve uma quantidade elementar das 


\section{CARACTERÍSTICAS BIBLIOMÉTRICAS E SOCIOMÉTRICAS DE PUBLICACCÕES DA ÁREA \\ AMBIENTAL EM CONGRESSOS E PERÍODICOS NACIONAIS \\ DOI: http://dx.doi.org/10.5007/1983-4535.2014v7n1p234}

mesmas. O número de estudos práticos foi proporcionalmente bastante superior aos teóricos em ambos os eventos, com destaque muito próximo ao estudo de caso e survey.

Tabela 3 Classificação dos artigos em estudos teóricos e práticos do período de 2000 a 2010

\begin{tabular}{|c|c|c|c|c|c|c|c|c|}
\hline \multirow[b]{2}{*}{ Classificação } & \multicolumn{2}{|c|}{ Congresso USP } & \multicolumn{2}{|c|}{ EnANPAD } & \multicolumn{2}{|c|}{ Periódicos } & \multirow[b]{2}{*}{ Total } & \multirow{2}{*}{$\begin{array}{l}\text { Total } \\
(\%)\end{array}$} \\
\hline & $\mathrm{f}$ & $\%$ & $\mathrm{f}$ & $\%$ & $\mathrm{f}$ & $\%$ & & \\
\hline Estudos Teóricos & 5 & 13,9 & 122 & 37,5 & 45 & 62,5 & 172 & 100 \\
\hline Conceitual & 2 & 5,6 & 69 & 21,2 & 20 & 27,8 & 91 & 53 \\
\hline Ilustrativo & 2 & 5,6 & 28 & 8,6 & 17 & 23,6 & 47 & 27 \\
\hline Conceitual aplicado & 1 & 2,8 & 25 & 7,7 & 8 & 11,1 & 34 & 20 \\
\hline Estudos Práticos & 31 & 86,1 & 203 & 62,5 & 27 & 37,5 & 261 & 100 \\
\hline Estudo de caso & 15 & 41,7 & 105 & 32,3 & 18 & 25,0 & 138 & 53 \\
\hline Survey & 16 & 44,3 & 98 & 30,2 & 9 & 12,5 & 123 & 47 \\
\hline Experimental & 0 & 0,0 & 0 & 0,0 & 0 & 0 & 0 & 0 \\
\hline Total & 36 & 100 & 325 & 100 & 72 & 100 & 433 & - \\
\hline
\end{tabular}

Fonte: Adaptado de Gallon et al. (2007) e dados da pesquisa.

Os periódicos, contrariamente ao que ocorre nos congressos, publicaram maior número de artigos com enfoque teórico, em detrimento aos estudos de caso e survey. Tal fato também foi constatado no estudo de Mathews (1997). Ressalta-se que não se identificaram publicações que utilizaram como estratégia de pesquisa estudos experimentais.

A Tabela 4 demonstra a classificação dos artigos de acordo com a fonte de coleta dos dados e o setor econômico das empresas em que as pesquisas foram aplicadas.

Tabela 4 Classificação dos artigos conforme fonte de coleta dos dados e setor de aplicação (2000 a 2010)

\begin{tabular}{l|l|l|l|l|l|l}
\hline \multicolumn{2}{l|}{ Classificação } & $\begin{array}{l}\text { Congresso } \\
\text { USP }\end{array}$ & EnANPAD & Periódicos & Total & $\begin{array}{l}\text { Total } \\
(\%)\end{array}$ \\
\hline \multirow{3}{*}{$\begin{array}{l}\text { Coleta de } \\
\text { Dados }\end{array}$} & Primário & 7 & 91 & 26 & $\mathbf{1 2 4}$ & $38 \%$ \\
& Secundário & 23 & 88 & 9 & $\mathbf{1 2 0}$ & $37 \%$ \\
& Primário - Secundário & 2 & 65 & 15 & $\mathbf{8 2}$ & $25 \%$ \\
\cline { 2 - 7 } & Total & $\mathbf{3 2}$ & $\mathbf{2 4 4}$ & $\mathbf{5 0}$ & $\mathbf{3 2 6}$ & $\mathbf{1 0 0 \%}$ \\
\hline \multirow{5}{*}{$\begin{array}{l}\text { Setor de } \\
\text { Aplicação }\end{array}$} & Privado & 16 & 108 & 31 & $\mathbf{1 5 5}$ & $50 \%$ \\
& Público & 1 & 41 & 7 & $\mathbf{4 9}$ & $16 \%$ \\
& $3^{\circ}$ Setor & 0 & 9 & 2 & $\mathbf{1 1}$ & $4 \%$ \\
& Público-Privado & 12 & 39 & 6 & $\mathbf{5 7}$ & $19 \%$ \\
\cline { 2 - 7 } & Público/Privado - 3 Setor & 2 & 33 & 0 & $\mathbf{3 5}$ & $11 \%$ \\
\cline { 2 - 7 } & Total & $\mathbf{3 1}$ & $\mathbf{2 3 0}$ & $\mathbf{4 6}$ & $\mathbf{3 0 7}$ & $\mathbf{1 0 0 \%}$ \\
\hline
\end{tabular}

Fonte: Adaptado de Gallon et al. (2007) e dados da pesquisa.

Constata-se na Tabela 4, que no Congresso USP predominaram estudos cuja coleta de dados deu-se por meio da análise de dados secundários, enquanto que no EnANPAD houve 


\section{CARACTERÍSTICAS BIBLIOMÉTRICAS E SOCIOMÉTRICAS DE PUBLICACCÕES DA ÁREA \\ AMBIENTAL EM CONGRESSOS E PERÍODICOS NACIONAIS \\ DOI: http://dx.doi.org/10.5007/1983-4535.2014v7n1p234}

uma relativa distribuição dos artigos entre as bases de coleta de dados. Nos periódicos, a maioria das publicações foram baseadas em dados primários ou mistos (primário-secundário).

No que diz respeito ao setor de atuação, no geral, houve uma predominância de pesquisas direcionadas ao setor privado, sendo que os demais setores apresentaram diferença em sua distribuição. O Congresso USP direcionou as publicações quase que exclusivamente ao setor privado e ao público-privado. No EnANPAD, embora tenha havido a predominância de estudos no setor privado, a exceção do $3^{\circ}$ setor, os demais setores apresentaram similar volume de publicações. Os periódicos priorizaram artigos cujo foco foi o setor privado.

Ressalta-se que nem todas as publicações puderam ser classificadas quanto ao setor, uma vez que 19 estudos não foram aplicados em empresas, mas sim em indivíduos (consumidores, turistas, estudantes, pesquisadores, empresários, dentre outros), similarmente ao que ocorreu no estudo de Gallon et al. (2007).

$\mathrm{Na}$ Tabela 5 apresenta-se a abordagem metodológica utilizada nas publicações pesquisadas.

Tabela 5 Abordagem metodológica utilizada nos artigos do período de 2000 a 2010

\begin{tabular}{l|l|l|l|l|l}
\hline Abordagem metodológica & $\begin{array}{l}\text { Congresso } \\
\text { USP }\end{array}$ & EnANPAD & Periódicos & Total & $\begin{array}{l}\text { Total } \\
(\mathbf{\%})\end{array}$ \\
\hline Qualitativa & 24 & 159 & 29 & 74 & $\mathbf{6 3 \%}$ \\
Quantitativa & 5 & 69 & 15 & 27 & $\mathbf{2 3 \%}$ \\
Qualitativa-quantitativa & 3 & 16 & 6 & 16 & $\mathbf{1 4 \%}$ \\
\hline Total & $\mathbf{3 2}$ & $\mathbf{2 4 4}$ & $\mathbf{5 0}$ & $\mathbf{1 1 7}$ & $\mathbf{1 0 0 \%}$ \\
\hline
\end{tabular}

Fonte: Adaptado de Gallon et al. (2007) e dados da pesquisa.

Depreende-se da Tabela 5, que nas publicações analisadas a abordagem metodológica mais utilizada foi a qualitativa (com 63\%), sendo que o Congresso USP teve 24 publicações, EnANPAD 159 e os periódicos analisados com 29 publicações sobre a área ambiental. Em seguida, tem-se a utilização da pesquisa quantitativa, com $23 \%$ das publicações. A abordagem qualitativa/quantitativa esteve presente em apenas $14 \%$ dos estudos.

Para a classificação das publicações por categoria temática foi adotada a divisão do estudo de Gallon et al. (2007), a saber: Contabilidade Ambiental, Evidenciação Ambiental, Gestão Ambiental e Sustentabilidade. Na Tabela 6 apresentam-se as características das publicações analisadas relativas às categorias temáticas. 


\section{CARACTERÍSTICAS BIBLIOMÉTRICAS E SOCIOMÉTRICAS DE PUBLICAÇÕES DA ÁREA AMBIENTAL EM CONGRESSOS E PERÍODICOS NACIONAIS DOI: http://dx.doi.org/10.5007/1983-4535.2014v7n1p234}

Tabela 6 Número de artigos por categoria temática do período de 2000 a 2010

\begin{tabular}{|c|c|c|c|c|c|c|c|c|c|c|}
\hline \multirow[b]{2}{*}{ Base de coleta } & \multicolumn{2}{|c|}{$\begin{array}{l}\text { Contabilidade } \\
\text { ambiental }\end{array}$} & \multicolumn{2}{|c|}{$\begin{array}{l}\text { Evidenciação } \\
\text { ambiental }\end{array}$} & \multicolumn{2}{|c|}{$\begin{array}{l}\text { Gestão } \\
\text { ambiental }\end{array}$} & \multicolumn{2}{|c|}{ Sustentabilidade } & \multirow[b]{2}{*}{ Total } & \multirow[b]{2}{*}{$\begin{array}{l}\text { Total } \\
(\%)\end{array}$} \\
\hline & $\begin{array}{ll}2000 & \text { a } \\
2006 & \end{array}$ & $\begin{array}{l}2007 \text { a } \\
2010\end{array}$ & $\begin{array}{l}2000 \text { a } \\
2006\end{array}$ & $\begin{array}{l}2007 \text { a } \\
2010\end{array}$ & $\begin{array}{l}2000 \text { a } \\
2006\end{array}$ & $\begin{array}{|ll|}2007 & \mathrm{a} \\
2010 & \\
\end{array}$ & $\begin{array}{ll}2000 & \mathrm{a} \\
2006 & \end{array}$ & $\begin{array}{ll}2007 & a \\
2010 & \\
\end{array}$ & & \\
\hline Congresso USP & 11 & 6 & 6 & 6 & 3 & 1 & 1 & 1 & 35 & $10 \%$ \\
\hline EnANPAD & 7 & 16 & 8 & 37 & 66 & 58 & 45 & - & 237 & $69 \%$ \\
\hline Periódicos & 3 & 1 & 0 & 4 & 25 & 13 & 11 & 16 & 73 & $21 \%$ \\
\hline Total & 21 & 23 & 14 & 47 & 94 & 72 & 57 & 17 & 345 & $100 \%$ \\
\hline \% sobre o total & $11,3 \%$ & $14,5 \%$ & $7,5 \%$ & $29,6 \%$ & $50,5 \%$ & $45,3 \%$ & $30,6 \%$ & $10,7 \%$ & - & 100 \\
\hline Média/ano & 3,0 & 5,7 & 2,0 & 11,8 & 8,6 & 18,0 & 8,1 & 4,3 & 31,4 & \\
\hline$\%$ geral & \multicolumn{2}{|l|}{$12,8 \%$} & \multicolumn{2}{|l|}{$17,7 \%$} & \multicolumn{2}{|l|}{$48,1 \%$} & \multicolumn{2}{|l|}{$21,4 \%$} & \multicolumn{2}{|l|}{$100 \%$} \\
\hline
\end{tabular}

Fonte: Adaptado de Gallon et al. (2007) e dados da pesquisa.

Nota-se na Tabela 6, que o tema Gestão Ambiental destacou-se dentre as categorias estabelecidas, ou seja, é o tema mais abordado $(48,1 \%)$ nas bases analisadas, no período considerado de onze anos. Segue-se a temática Sustentabilidade, com 21,4\% dos artigos.

Porém, ao analisar a evolução das pesquisas, de 2000 a 2006 e de 2007 a 2010, percebe-se que há uma alteração em relação a média geral, em que se destaca uma leve redução dos estudos em Gestão Ambiental, um declínio maior nos estudos sobre Sustentabilidade e um aumento nos estudos direcionados a Evidenciação Ambiental.

Nos periódicos analisados os temas Evidenciação Ambiental e Sustentabilidade evoluíram ao longo do período. No Congresso USP nenhum dos temas apresentou evolução no período considerado. O EnANPAD apresentou elevado aumento nos estudos socializados relacionados ao tema Evidenciação Ambiental, seguido em menor volume pelos temas Gestão Ambiental e Contabilidade Ambiental, porém, não socializou no período de 2007 a 2010 nenhum artigo enfocando o tema Sustentabilidade.

\subsection{CONFIGURAÇÃO ESTRUTURAL DOS RELACIONAMENTOS}

Neste tópico apresenta-se a análise realizada por meio da técnica de redes sociais. Wasserman e Faust (1994) apontam que as redes sociais podem ser definidas como um conjunto de dois elementos: atores (pessoas, instituições ou grupos) e suas conexões. Tureta, Reis e Ávila (2006) destacam que as redes vêm sendo utilizadas para a investigação de múltiplos fenômenos que envolvem relacionamentos colaborativos entre diversos atores. A Figura 1 apresenta a configuração da rede entre autores e local da socialização e publicação para as categorias temáticas de Contabilidade Ambiental e Evidenciação Ambiental. 


\section{CARACTERÍSTICAS BIBLIOMÉTRICAS E SOCIOMÉTRICAS DE PUBLICACCÕES DA ÁREA AMBIENTAL EM CONGRESSOS E PERÍODICOS NACIONAIS \\ DOI: http://dx.doi.org/10.5007/1983-4535.2014v7n1p234}

Em relação à Contabilidade Ambiental, na Figura 1 observa-se que a configuração estrutural dos relacionamentos dos autores nos congressos aparecem em predominância. $\mathrm{O}$ EnANPAD apresentou 45 autores com publicações sobre contabilidade ambiental, seguido do Congresso USP com 36. Dos periódicos analisados, nota-se que apenas a Revista Contabilidade \& Finanças (RC\&F) teve publicações, com 5 autores nessa categoria, a saber: SANTOS, A. O. et al; SOUZA, V. R.; RIBEIRO, M. S.; COSTA, R. S.; e MARION, J. C.

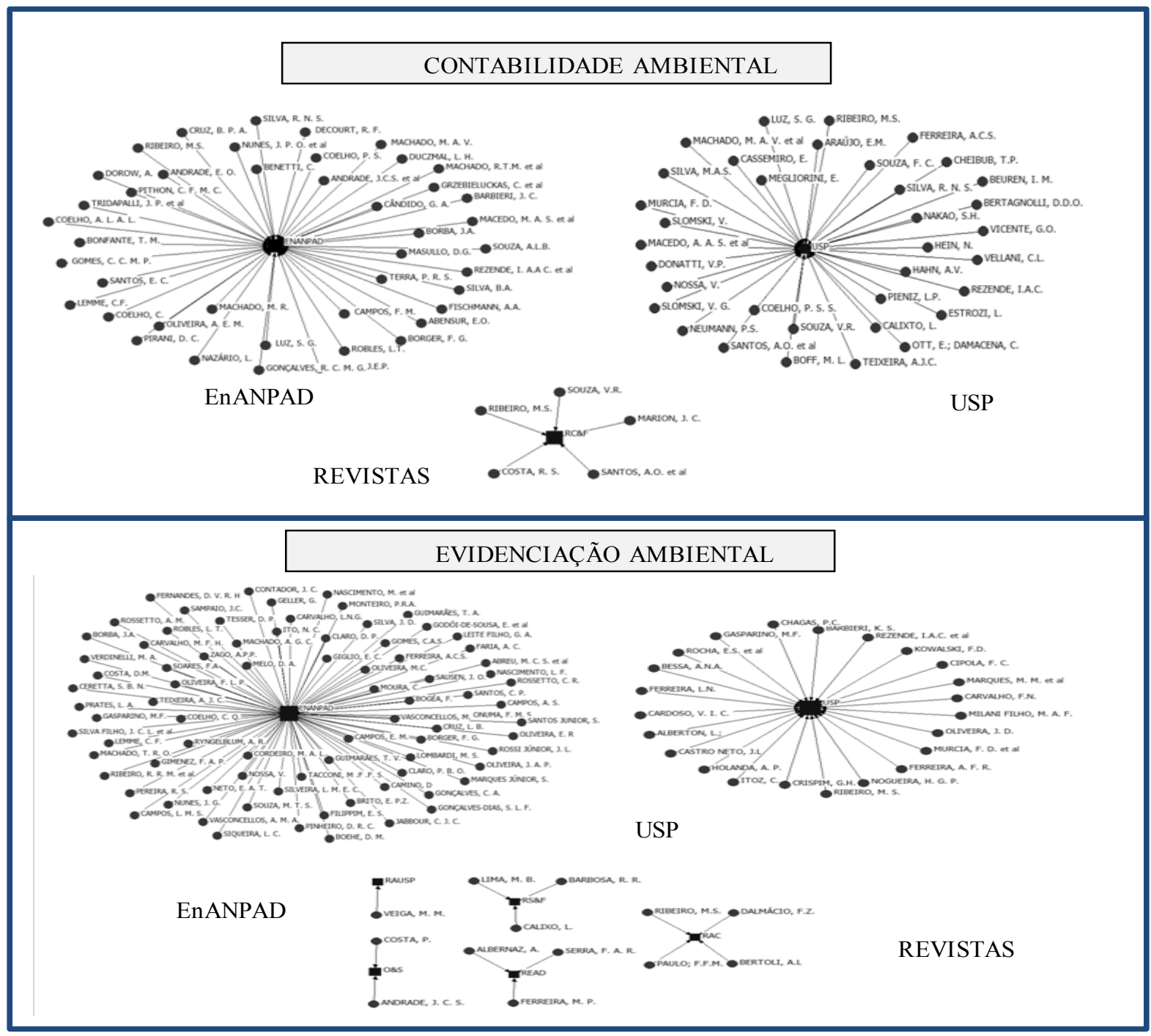

Figura 1 Redes sociais dos autores com publicações nas categorias temáticas de Contabilidade Ambiental e Evidenciação Ambiental Fonte: Dados da pesquisa.

No que diz respeito à Evidenciação Ambiental, é possível visualizar uma maior concentração de publicações sobre essa categoria no EnANPAD, com participação de 83 autores. Além disso, a temática apresentou-se pulverizada em detrimento de um numero baixo de publicações em periódicos, apresentando-se de forma dispersa em diferentes periódicos, 


\section{CARACTERÍSTICAS BIBLIOMÉTRICAS E SOCIOMÉTRICAS DE PUBLICACCÕES DA ÁREA \\ AMBIENTAL EM CONGRESSOS E PERÍODICOS NACIONAIS \\ DOI: http://dx.doi.org/10.5007/1983-4535.2014v7n1p234}

como segue: RAUSP (1 autor), RC\&F ( 3 autores), O\&S (2 autores), REAd (3 autores) e RAC (4 autores).

$\mathrm{Na}$ sequência da análise por meio de redes, a Figura 2 mostra a formação das estruturas sociais entre os autores que publicaram sobre Gestão Ambiental e Sustentabilidade.

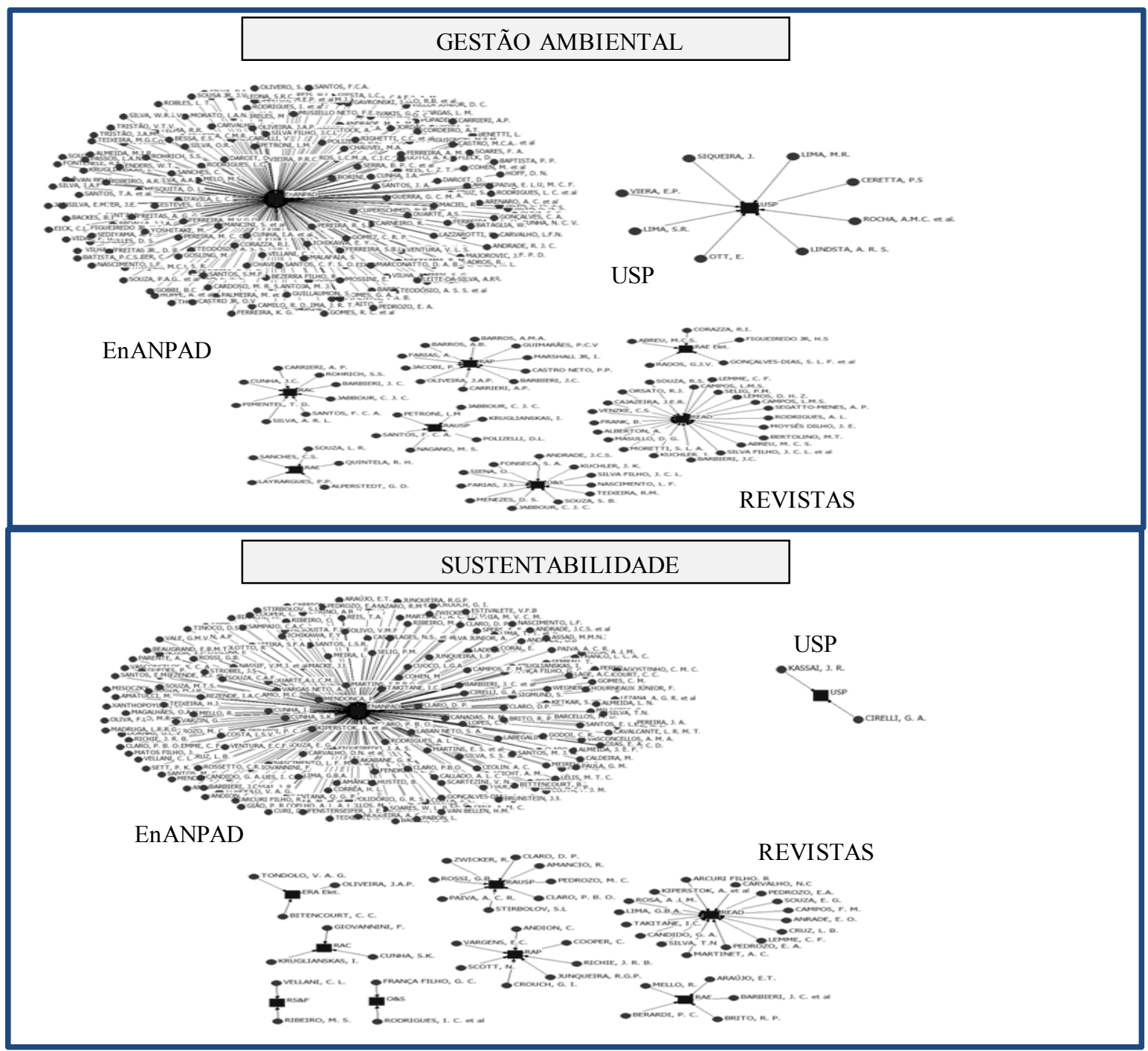

Figura 2 Redes sociais dos autores com publicações nas categorias temáticas de Gestão Ambiental e Sustentabilidade

Fonte: Dados da Pesquisa.

Em ambas as áreas temáticas, nota-se na Figura 2 a predominância da rede representada pelo EnANPAD. Em relação à Gestão Ambiental percebe-se uma forte centralização no EnANPAD, com laços entre os 234 autores, de forma oposta ao Congresso USP, em que as redes não estão presentes. Dentre os periódicos pesquisados, a REAd apresentou a maior quantidade de publicações, com 22 ligações entre os autores. 


\section{CARACTERÍSTICAS BIBLIOMÉTRICAS E SOCIOMÉTRICAS DE PUBLICACCÕES DA ÁREA AMBIENTAL EM CONGRESSOS E PERÍODICOS NACIONAIS DOI: http://dx.doi.org/10.5007/1983-4535.2014v7n1p234}

Na temática Sustentabilidade, a predominância do EnANPAD ocorre com um elevado número de artigos socializados, comparativamente aos demais, com 182 relacionamentos entre os autores nas publicações analisadas. Denota-se que essa forma estrutural apresenta-se fortemente concentrada, onde existem autores que se aglutinam entre si.

$\mathrm{Na}$ configuração dos laços dos periódicos observa-se que se encontram pulverizados entre os 8 periódicos analisados. Nos periódicos RC\&f e RAE Elet os laços apresentam-se de forma isolada na rede,com apenas 2 ligações entre os autores; na RAE Elet. há laços entre 3 autores, similarmente na RAC, com a mesma participação; a RAE apresentou 5 laços; a RAP e RAUSP apresentaram respectivamente 7 e 8 autores; a maior concentração do número de laços dos autores consta no periódico REAd, com 16 ligações.

De maneira geral, observa-se que alguns autores aparecem conectados com mais de um laço, podendo integrar várias fontes de base de coleta de dados em diferentes períodos da análise, por terem publicado artigos sobre mais de uma das categorias desta pesquisa. Cita-se a título de ilustração os autores MACHADO, M. A. V. et al.; REZENDE, I. A. C.; RIBEIRO, M. S.; SILVA, R. N. S.; LEMME, C. F.; NOSSA, V.; TEIXEIRA, A. J. C.

Considerando-se que os periódicos configuram-se como a forma definitiva de disseminação dos conhecimentos, a Figura 3 apresenta a configuração estrutural dos relacionamentos entre os autores com publicações nos 8 periódicos pesquisados.

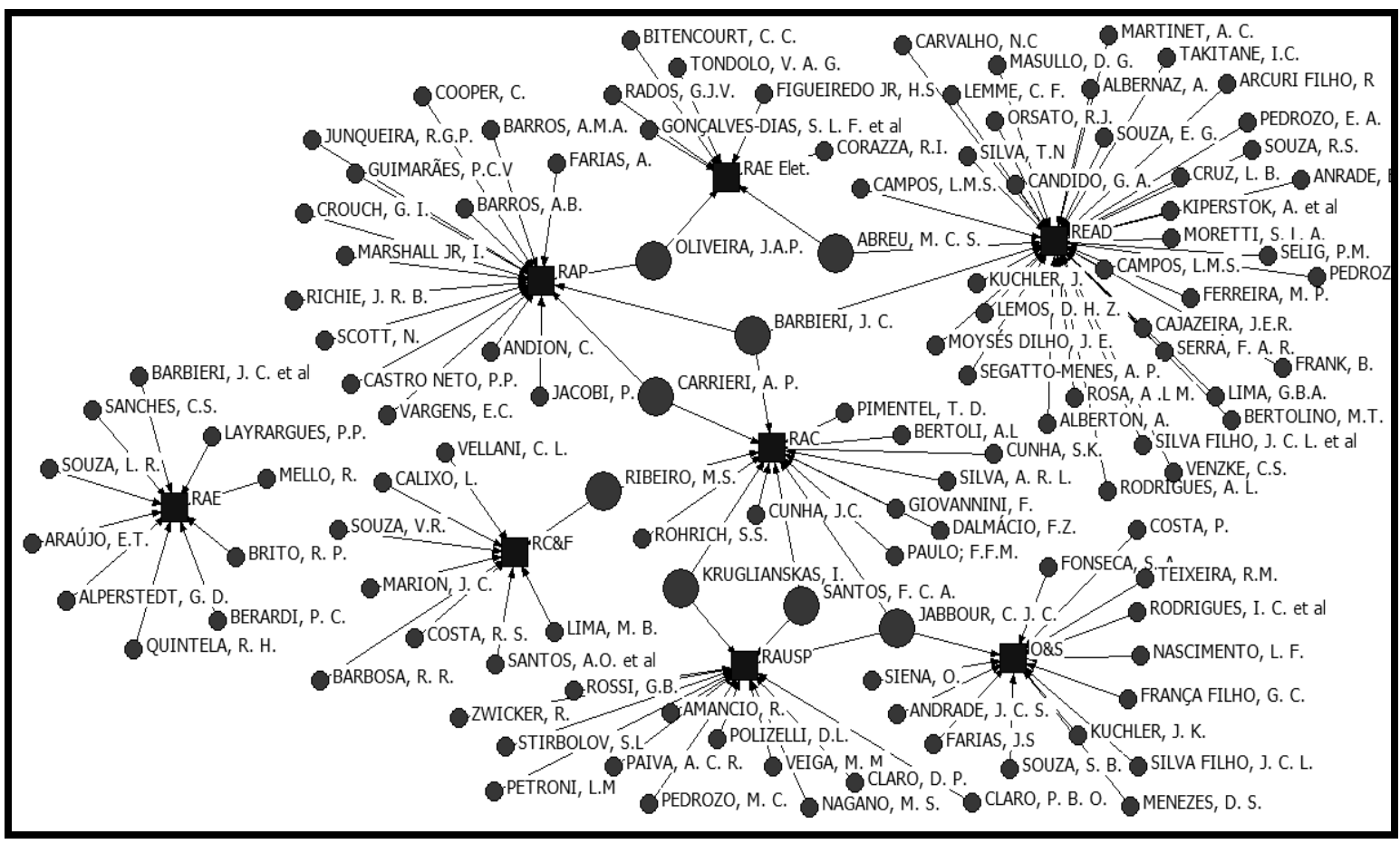

Figura 3 Redes sociais dos autores com publicações em periódicos Fonte: Dados da pesquisa. 


\section{CARACTERÍSTICAS BIBLIOMÉTRICAS E SOCIOMÉTRICAS DE PUBLICACCÕES DA ÁREA AMBIENTAL EM CONGRESSOS E PERÍODICOS NACIONAIS \\ DOI: http://dx.doi.org/10.5007/1983-4535.2014v7n1p234}

Observa-se na Figura 3 que há alguns autores que possuem laços de publicações com autores de outros periódicos, ou seja, as publicações apresentam-se de forma pulverizada em 7 periódicos. A exemplo disso, destaca-se o periódico REAd, que possui maior número de laços entre os autores, bem como ligações com outros periódicos. Cita-se como exemplo a RAE Elet. com a RAP, por meio das publicações de ABREU, M. C. S. e BARBIERI, J. C., respectivamente. Complementarmente, observa-se o mesmo nas redes da RAP, RC\&F, RAUSP e O\&S.

Em adição a essa análise, destaca-se na Tabela 7 a quantidade de laços dos autores que tiveram publicações em diferentes periódicos, sobre temáticas diferentes.

Tabela 7 Quantidade de laços dos autores nos periódicos

\begin{tabular}{l|l|l|l}
\hline \multicolumn{2}{l|}{ Autores } & Periódicos & $\mathbf{N}^{\circ}$ laços \\
\hline 1 & BARBIERI, J. C. & REAd, RAP, RAC & 3 \\
\hline 2 & JABBOUR, C. J. C. & RAC, RAUSP, O\&S & 3 \\
\hline 3 & ABREU, M. C. S. & REAd, RAE Elet. & 2 \\
\hline 4 & CARRIERI, A. P. & RAP, RAC & 2 \\
\hline 5 & KRUGLIANSKAS, I. & RAC, RAUSP & 2 \\
\hline 6 & OLIVEIRA, J. A. P. & RAP, RAE Elet. & 2 \\
\hline 7 & RIBEIRO, M. S. & RC\&F, RAC & 2 \\
\hline 8 & SANTOS, F., C. A. & RAC, RAUSP & 2 \\
\hline Total & & $\mathbf{1 8}$ \\
\hline
\end{tabular}

Fonte: Dados da pesquisa.

Percebe-se na Tabela 7 que dois autores aparecem com maior quantidade de laços no que tange aos relacionamentos com os demais autores em outros periódicos. Os autores BARBIERI, J. C. e JABBOUR, C. J. C. foram os que apresentaram maior numero de laços, com 3 cada. Denota-se também que o periódico RAC apresentou-se distribuído em 6 redes, seguido dos periódicos RAUSP (em 3 redes), RAP (em 3 redes, RAE Elet. (em 2 redes), READ (em 2 redes), O\&S (em 2 redes) e RC\&F (em 1 rede). Ademais verificou-se que a revista RAE foi a única que não apresentou ligações entre os autores das publicações constantes nas demais revistas.

$\mathrm{Na}$ Tabela 8 apresentam-se os autores com maior produtividade sobre a temática ambiental nos eventos e periódicos pesquisados, no período de analisado. 


\section{CARACTERÍSTICAS BIBLIOMÉTRICAS E SOCIOMÉTRICAS DE PUBLICACCÕES DA ÁREA AMBIENTAL EM CONGRESSOS E PERÍODICOS NACIONAIS DOI: http://dx.doi.org/10.5007/1983-4535.2014v7n1p234}

Tabela 8 Autores com maior número de publicações no período

\begin{tabular}{l|l|l|l|l|l}
\hline Nome & $\mathbf{N}^{\mathbf{0}}$ public. & Vínculo & Nome & $\mathbf{N}^{\mathbf{0}}$ public. & Vínculo \\
\hline LEMME, C. F. & 7 & UFRJ & CARRIERI, A. P. & 5 & UFMG \\
\hline RIBEIRO, M. S. & 9 & USP & CLARO, D. P & 5 & IBMEC \\
\hline BARBIERI, J. C. & 8 & FGV & DAROIT, D. & 5 & UFRGS \\
\hline SILVA FILHO, J. C. L. & 7 & UFC & NOSSA, V. & 4 & FUCAPE \\
\hline NASCIMENTO, L. F. & 6 & UFRGS & PEDROZO, E. A. & 4 & UFRGS \\
\hline OLIVEIRA, J. A.P. & 6 & FGV & REZENDE, I. A. C & 4 & FUCAPE \\
\hline VAN BELLEN, H. M & 7 & UFC & SANTOS, F. C. A. & 4 & USP \\
\hline CLARO, P. B. O & 6 & IBMEC & SELIG, P. M. & 4 & UFSC \\
\hline JABBOUR, C. J. C. & 6 & UNESP & SILVA, T. N. & 4 & UFRGS \\
\hline ABREU, M. C. S. & 6 & UFSC & SOUZA, M. T. S. & 4 & UNINOVE \\
\hline ANDRADE, J. C. S. & 5 & UFBA & TEIXEIRA, R. M. & 4 & UFPR \\
\hline CAMPOS, L. M. S. & 5 & UNIVALI & TOTAL & $\mathbf{1 2 5}$ & \\
\hline
\end{tabular}

Fonte: dados da pesquisa

No que se refere à autoria dos artigos da amostra, no período analisado foram identificados 575 autores. Destes, os mais produtivos estão elencados na Tabela 8. Registra-se que esses 23 pesquisadores respondem, juntos, por 33,6\% do total de publicações analisadas. Em relação aos vínculos institucionais, a UFRGS destaca-se por ter quatro autores com maior número de publicações sobre a temática ambiental.

$\mathrm{Na}$ Tabela 9 apresentam-se em ordem decrescente o título e os autores das dez referências mais citadas pelos estudos analisados.

Tabela 9 Obras mais referenciadas nas publicações analisadas

\begin{tabular}{l|l|l}
\hline Título & Ano & Autor(es) \\
\hline $\begin{array}{l}\text { The Social Responsibility of Business is to Increase its } \\
\text { Profits }\end{array}$ & 1970 & FRIEDMAN, M. \\
\hline Corporate social performance revisited. & 1991 & WOOD, D. J. \\
\hline Contabilidade e meio ambiente & 1992 & RIBEIRO, M. S. \\
\hline Gestão ambiental na empresa & 1995 & DONAIRE, D. \\
\hline Green and competitive & 1995 & PORTER, M.; LINDE, C. V. \\
\hline Passaporte verde: gestão ambiental e competitividade & 1996 & MAIMOM, D. \\
\hline Custeio das atividades de natureza ambiental & 1998 & RIBEIRO, M. S. \\
\hline $\begin{array}{l}\text { Gestão ambiental - enfoque estratégico aplicado ao } \\
\text { desenvolvimento sustentável }\end{array}$ & 2000 & $\begin{array}{l}\text { BNDRADE, R. O. B., CARVALHO, A. } \\
\text { Cannibals with forks, Capstone Publishing }\end{array}$ \\
\hline $\begin{array}{l}\text { Gestão Ambiental Empresarial: conceitos, modelos e } \\
\text { instrumentos. }\end{array}$ & 2000 & ELKINGTON, J. \\
\hline
\end{tabular}

Fonte: Dados da Pesquisa.

A listagem apresentada na Tabela 9, com obras mais citadas e seus respectivos autores, permite inferir que há uma tendência nas pesquisas analisadas de referenciar obras consideradas clássicas. Depreende-se isso ao se observar o ano de publicação de algumas 


\section{CARACTERÍSTICAS BIBLIOMÉTRICAS E SOCIOMÉTRICAS DE PUBLICACCÕES DA ÁREA \\ AMBIENTAL EM CONGRESSOS E PERÍODICOS NACIONAIS \\ DOI: http://dx.doi.org/10.5007/1983-4535.2014v7n1p234}

obras citadas, como as de FRIEDMAN, M. (1970), WOOD, D. J. (1991), RIBEIRO, M. S. (1992) e DONAIRE, D. (1995).

\section{CONCLUSÕES}

O estudo objetivou examinar características bibliométricas e sociométricas de publicações da área ambiental no Congresso USP de Controladoria e Contabilidade, EnANPAD e em periódicos de Administração e Contabilidade no período de 2000 a 2010. Pesquisa descritiva com abordagem quantitativa foi realizada por meio de pesquisa documental, tendo como base ambos os eventos científicos mencionados e um total de oito periódicos, que também fundamentaram a pesquisa de Gallon et al. (2007).

Os resultados da pesquisa bibliométrica mostraram um crescimento nas publicações da área da temática ambiental, nos documentos pesquisados relativos ao período de 2000 a 2010. Constatou-se que as pesquisas na área de administração e contabilidade, na base analisada, evoluiram significativamente, impulsionadas principalmente pelo expressivo aumento de artigos socializados no EnANPAD, que passou de dois artigos sobre o tema socializados no ano de 2000 para 53 em 2010. Registra-se também que, a partir de 2006, houve um constante aumento no volume de artigos socializados sobre o tema. Já no Congresso USP o volume de artigos socializados sobre a temática ambiental tem se mantido, em média, na ordem de três artigos por evento.

Em relação à publicação em periódicos, no geral, o volume manteve-se estável, porém, ao analisar cada publicação separadamente, observou-se que a RAC, RAE Elet. e RC\&F foram os periódicos que apresentaram o menor volume de publicações. A RAP, embora tenha totalizado um número expressivo de publicações, comparativamente aos demais periódicos, apresentou uma curva de tendência de crescimento negativa, o que talvez possa sinalizar que o periódico tenha deixado de publicar artigos sobre o tema. Porém, o oposto acontece com os periódicos O\&S, RAE, RAUSP e REAd, que possuem uma curva de tendência ascendente em relação ao volume de publicações sobre o tema.

No que concerne às metodologias de pesquisa adotadas, averiguou-se que o Congresso USP e o EnANPAD tenderam a priorizar estudos empíricos, basicamente estudos de caso e survey, enquanto que nos periódicos prevaleceram estudos teóricos. A pesquisa empírica na área ambiental, embora tenha apresentado baixo nível de publicações nos periódicos, é relevante. Segundo Mathews (1997), a pesquisa empírica se constitui como um registro do 


\section{CARACTERÍSTICAS BIBLIOMÉTRICAS E SOCIOMÉTRICAS DE PUBLICAÇÕES DA ÁREA \\ AMBIENTAL EM CONGRESSOS E PERÍODICOS NACIONAIS \\ DOI: http://dx.doi.org/10.5007/1983-4535.2014v7n1p234}

estado atual presente nas organizações, possibilitando visualizar-se a distância que ainda necessita ser percorrida para a plena responsabilidade dos agentes econômicos no que tange à construção de uma sociedade sustentável.

Sobre a categoria da temática ambiental dos estudos investigados, em que se seguiu a mesma classificação adotada por Gallon et al. (2007), verificou-se que: a Contabilidade Ambiental esteve presente com maior intensidade nos congressos; a Evidenciação Ambiental predominou também nos congressos; a Gestão Ambiental representou a maioria dos estudos socializados no EnANPAD e publicados nos periódicos; o tema Sustentabilidade praticamente não apresentou socializações nos congressos a partir de 2007, no entanto, foi a categoria que predominou nos artigos publicados em periódicos.

Em síntese, os resultados da pesquisa bibliométrica destacaram que: i) o volume de publicações sobre o tema no EnANPAD aumentou significativamente no decorrer do período analisado; ii) os periódicos O\&S, RAE, RAUSP e REAd apresentam uma curva de tendência ascendente no volume de publicações sobre o tema; iii) quanto a metodologia adotada nas pesquisas, o Congresso USP e o EnANPAD priorizaram estudos de caso e survey e os periódicos estudos teóricos, mas em todos prevaleceu a abordagem qualitativa e o setor privado como campo da pesquisa; iv) dentre as categorias da temática ambiental prevaleceu a Gestão Ambiental e uma evolução gradual nas publicações sobre Evidenciação Ambiental.

Os resultados da pesquisa sociométrica revelaram que a configuração estrutural dos relacionamentos dos autores prepondera nos congressos. Também evidenciou que há alguns autores que possuem laços de publicações com autores de outros periódicos, ou seja, as publicações apresentam-se de forma pulverizada e com lacunas principalmente em periódicos.

Pesquisa bibliométrica e sociométrica realizada por Parker (2011) em periódicos internacionais sobre esta temática demonstrou que as pesquisas em contabilidade social e ambiental continuam em evidência, com pesquisadores oriundos de diversos países, e, em maior intensidade da Europa e da Austrália e em menor intensidade da América do Norte. O autor, adicionalmente, comenta que a área está solidificada em redes de pesquisadores com periódicos e congressos específicos, o que indica boas perspectivas para o futuro.

Comparando-se os resultados obtidos na amostra analisada em eventos brasileiros e periódicos nacionais, com os achados de Parker (2011), conclui-se que, no Brasil, a exemplo do que ocorreu nas pesquisas internacionais, a área ambiental tem evoluído e se consolidado. Tal afirmativa advém do volume de publicações localizadas (395) e de autores envolvidos 


\section{CARACTERÍSTICAS BIBLIOMÉTRICAS E SOCIOMÉTRICAS DE PUBLICAÇÕES DA ÁREA \\ AMBIENTAL EM CONGRESSOS E PERÍODICOS NACIONAIS \\ DOI: http://dx.doi.org/10.5007/1983-4535.2014v7n1p234}

(575). Em relação às instituições, a UFRGS destacou-se por concentrar o maior número de pesquisadores com maior produtividade na temática ambiental.

Conclui-se com base no estudo que examinou características bibliométricas e sociométricas de publicações da área temática ambiental por meio de trabalhos socializados no Congresso USP de Controladoria e Contabilidade e no EnANPAD e de artigos publicados em periódicos da área de Administração e Contabilidade, no período de 2000 a 2010, que o tema continua em evidência e que a configuração estrutural dos relacionamentos dos autores apresenta-se com lacunas e de forma pulverizada principalmente nos periódicos pesquisados.

Futuras pesquisas, cujo interesse seja o de socializar em congresso, podem abordar questões empíricas que tendem a ter melhor aceitação no EnANPAD, comparativamente ao Congresso USP. No entanto, para que seja possível publicar estudos sobre a temática ambiental é necessário fugir do que Mathews (1997) classificou como pesquisas com metodologia fraca, que geram resultados triviais ou não confiáveis, sem uma adequada relação com as teorias organizacionais. Em adição, futuras pesquisas, em qualquer categoria, podem ser direcionadas para estudos envolvendo organizações do terceiro setor e, especificamente, a categoria de sustentabilidade em qualquer setor econômico.

\section{REFERÊNCIAS}

BEBBINGTON, J.; GRAY, R. An account of sustainability: failure, success and a reconceptualization. Critical Perspectives on Accounting. v. 12, p. 557-587, 2001.

BELAL, A. R. A study of corporate social disclosures in Bangladesh. Managerial Auditing Journal. v. 16, n. 5, p. 274-289, 2001.

BOWEN, H.R. Social responsibilities of the businessman. New York: Harper \& Row, 1953.

CALIXTO, L. Uma análise da evidenciação ambiental de companhias brasileiras: de 1997 a 2005. UnB Contábil, Brasília, v. 10, n 1, jan./jun. 2007.

COMISSÃO MUNDIAL SOBRE O MEIO AMBIENTE. Assembleia geral. Dez. 1987. Disponível em: < http://www.un.org/documents/ga/res/42/ares42-187.htm>. Acesso em: 26 ago. 2011.

GALLON, A.V; SOUZA, F. C.; ROVER, S.; VAN BELLEN, H. M. Produção científica e perspectivas teóricas da área ambiental: um levantamento a partir de artigos publicados em congressos e periódicos nacionais da área de Contabilidade e Administração. In:

CONGRESSO USP DE CONTABILIDADE E FINANÇAS, 7., 2007, São Paulo. Anais... São Paulo, FEA/USP, 2007. 
. Um estudo longitudinal da produção científica em Administração direcionada à temática ambiental. Alcance. Florianópolis, v. 15, p. 81-101, 2008.

GONÇALVES, S.S.; HELIODOR, P. A. A contabilidade ambiental como um novo paradigma. Revista Universo Contábil, Blumenau, v. 1, n. 3, p. 81-93, set./dez. 2005.

GONZALES, C. L.; BEBBINGTON, J. Accounting change or institutional appropriation? a case study of the implementation of environmental accounting. Critical Perspectives on Accounting. v. 12, p. 269-292, 2001.

GRAY, R; BEBBINGTON, J.; WALTERS, D. Accounting for the environment. London: Paul Chapman, 1993. Disponível em: <http://books.google.com/books>. Acesso em: 28 ago. 2011.

GRAY, R.; KOUHY, R.; LAVERS, S. Corporate social and environmental reporting: a review of the literature and a longitudinal study of UK disclosure. Accounting, Auditing \& Accountability Journal, v. 8, n. 2, p. 47-77, 1995.

JACOBI, P. Educação ambiental, cidadania e sustentabilidade. Caderno de Pesquisa, n. 18, p. 189-205, mar. 2003.

MATHEWS, M. R. Twenty-five years of social and environmental accounting research: is there a silver jubilee to celebrate? Accounting, Auditing \& Accountability Journal. v. 10, n. 4, p. 481-531, 1997.

MURCIA, F. D. R; SANTOS, A.; SALOTTI, B. M.; NASCIMENTO, A. Mapeamento da pesquisa sobre disclosure ambiental no cenário internacional: uma revisão dos artigos publicados em periódicos de língua inglesa no período de 1997 a 2007. ConTexto. Porto Alegre, v. 10, n. 17, p. 7-18, $1^{\circ}$ sem. 2010.

PARKER, L. Social and environmental accountability research: a view from the commentary box . Accounting, Auditing \& Accountability Journal. v. 18, n. 6, p. 842-860, 2005.

PARKER, L. Twenty-one years of social and environmental accountability research: a coming of age. Accounting Forum. v. 35, n. 1, p. 1-10, March, 2011.

PONTE, V. M. R.; OLIVEIRA, M. C.; MOURA, H.; CARMO, R.C.A. Análise das práticas de evidenciação de informações obrigatórias, não-obrigatórias e avançadas nas demonstrações contábeis das sociedades anônimas no Brasil: um estudo comparativo dos exercícios de 2002 e 2005. Revisa de Contabilidade \& Finanças, USP, São Paulo, v. 18, n. 45, p. 50-62, set./dez. 2007,

SGARBI, V. S.; LIMA, M. T. A.; SANTOS, C. F. S. O.; FALCÃO, M. C. Os jargões da sustentabilidade: uma discussão a partir da produção científica nacional. In: ENCONTRO NACIONAL DE GESTÃO EMPRESARIAL E MEIO AMBIENTE, 8., 2008, Porto Alegre. Anais... São Paulo, FGV, 2008. 
SANTOS, A. R. P.; ROCHA, A.; SANTOS, E. C. A.; SANTOS, R. G. Contabilidade ambiental: uma contribuição da ciência contábil a sustentabilidade da gestão ambiental. In: SEMINÁRIOS EM ADMINISTRAÇÃO, 9., 2006, São Paulo. Anais... São Paulo, FEA/USP, 2006.

SOUZA, V. R.; RIBEIRO, M. S. Aplicação da contabilidade ambiental na indústria madeireira. Revista Contabilidade \& Finanças, São Paulo, n. 35, p. 54-67, maio/ago. 2004.

Tureta, C.; Reis, A.; Ávila, S. Da teoria sistêmica ao conceito de redes interorganizacionais: um estudo exploratório da teoria das organizações. Revista de Administração da Unimep, v. 4, n. 1, jan./abr. 2006.

VERGARA, S. C. Projetos e relatórios de pesquisa em administração. 2. ed. São Paulo: Atlas, 1998.

WASSERMAN, S.; FAUST, K. Social network analysis: methods and applications. New York: Cambridge Press, 1994. 